\title{
Judicialização da política ou politização da justiça? Uma Análise Crítica do Discurso do Libelo Acusatório contra a presidenta Dilma Rousseff no processo de impeachment
}

\author{
Judicialization of Politics or Politicization of Justice? \\ A Critical Discourse Analysis of the Bill of Indictment against \\ President Dilma Rousseff in the Impeachment Trial
}

Georg WINK*

Universidade de Copenhague (UCPH)

\begin{abstract}
RESUMO: Este estudo interdisciplinar trata do libelo acusatório, apresentado contra a presidenta ${ }^{1}$ Dilma Rousseff, como fundamento para o julgamento pelo júri do Senado Federal, na última fase do processo de impeachment. O objetivo é examinar e problematizar as práticas discursivas usadas neste texto chave jurídico e as suas funções no âmbito de um processo que é definido mais amplamente como jurídico-político. $\mathrm{O}$ embasamento teórico consiste numa releitura crítica do conceito de judicialização da política, que implica, reciprocamente, uma politização da justiça, ainda mais patente quando aplicada ao contexto brasileiro. O emprego de métodos oriundos da Análise Crítica do Discurso demonstra que o libelo acusatório desvia-se substancialmente do padrão do gênero textual, pelo uso sistemático de estratégias retóricas de persuasão, próprias do campo político.
\end{abstract}

PALAVRAS-CHAVE: Politização da Justiça. Brasil. Impeachment. Libelo Acusatório. Análise Crítica do Discurso.

ABSTRACT: The subject of interdisciplinary research of this article is the Bill of Indictment against President Dilma Rousseff which was presented to the Jury of the Federal Senate as grounds for her judgement during the last phase of the impeachment trial. My objective is to examinate and problematize the discursive practices used in this juridical core text with regard to their functions within a process defined more broadly as juridical-political. My theoretical approach is based on a critical rereading of the concept of Judicialization of Politics which implies reciprocally in an Politicization of Justice, which becomes still more blatant when applied to the Brazilian context. It is shown by using methods of Critical Discourse Analysis that the Bill of Indictment aberrates substantially from the text-type conventions, as for the systematic use of political field related rhetorical strategies of persuasion.

KEYWORDS: Politicization of Justice. Brazil. Impeachment. Indictment. Critical Discourse Analysis.

\footnotetext{
${ }^{1}$ Utiliza-se, neste trabalho, a denominação oficial do cargo durante o exercício do mandato de Dilma Rousseff, independentemente de considerações estilísticas.

*Professor Associado de Estudos Brasileiros na Universidade de Copenhague, Faculdade de Humanidades, Departamento de Estudos Portugueses e Brasileiros, Copenhague, Dinamarca. E-mail de contato: georg.wink@hum.ku.dk.
} 


\section{Introdução}

Boaventura de Sousa Santos

Em vários momentos, durante o processo jurídico-político do "impeachment"2, um observador crítico pode ter ficado na dúvida sobre os marcos limitadores entre o jurídico e o político, além de estranhar a interação e mescla dos dois campos. Se era para ser um processo jurídico, presidido pelo presidente do Supremo Tribunal Federal (em seguida STF), por que predominavam discursos justificativos de evidente cunho político? E, se era para ser um processo político, tendo como júri os Senadores da República, qual era a necessidade de recorrer à nomenclatura, aos princípios e ao rito do processo jurídico? O presente trabalho pretende abordar as transgressões errantes entre os campos do jurídico e do político, supostamente regidos por códigos diferentes, com foco numa peça de importância central para o desfecho do processo, o libelo acusatório contra a presidenta Dilma Rousseff, que abriu a última fase do "impeachment" e serviu como fundamento para o seu julgamento. Toma-se como ponto de partida a teoria da judicialização da política, no sentido da delegação de poder ao judiciário, um fenômeno que vem sendo estudado desde os anos 1990 e que tem chamado, ultimamente, a atenção, especialmente das Ciências Sociais, também para o seu lado problemático. Fazendo uma releitura crítica, examina-se a aplicabilidade desta teoria ao contexto da Nova República Brasileira, com atenção especial ao acionismo jurídico do STF, estabelecendo a hipótese de que a judicialização da política está reciprocamente relacionada com uma politização da justiça, pelo estado da arte ainda menos contemplada e carente de uma definição. A seguir, com base num conceito reformulado de politização da justiça stricto sensu, discute-se a representatividade, a viabilidade e as restrições do estudo de caso, que consiste numa análise crítica do discurso do libelo acusatório, e apresenta-se o aparato metodológico. É mister esclarecer, desde o início, que as ferramentas usadas não permitirão averiguar se a argumentação apresentada no texto jurídico é procedente, pois o objetivo é unicamente verificar a politização do

\footnotetext{
${ }^{2}$ Utiliza-se, aqui e em diante, marcação entre aspas para expressar que o processo que levou ao afastamento da presidenta Dilma Rousseff, embora tenha sido comumente chamado de impeachment, não necessariamente cumpre com os requisitos que definem, legalmente, um processo de impeachment - o que será demonstrado pelos resultados deste trabalho, pelo menos em relação ao requisito da presença do elemento jurídico no libelo acusatório.
} 
discurso empregado, mais concretamente em relação às estratégias de persuasão empregadas. Não obstante, seguindo um raciocínio inverso, será explorada a questão se a opção pela retórica, inusitada no gênero textual, não poderia apontar para uma falta de evidência e credibilidade dos "fatos" alegados, o que significaria uma desqualificação, pelo menos parcial, do lado jurídico do processo do "impeachment". Sendo assim, corroboraria a hipótese inicial sobre a existência de indícios robustos de uma politização da justiça no Brasil.

\section{A judicialização da política}

A “judicialização da política" é um fenômeno universal. O conceito comporta, de forma genérica, a interferência crescente do judiciário em questões e decisões políticas, que vai claramente além do mero tratamento de transgressões ilegais no âmbito político e da mobilização do judiciário pela sociedade civil (COMMAILLE, 2009, p. 104-106). Na definição já clássica de VALLINDER (1995, p. 13), abrange tanto a transferência das decisões do executivo e legislativo para o jurídico, como também a incorporação de métodos judiciais no campo político, resultando numa expansão global do poder judiciário face aos poderes legislativo e executivo. $\mathrm{O}$ fenômeno foi problematizado pelo levantamento da hipótese de que este acúmulo de poder, com destaque para os Supremos Tribunais, poderia indicar um desequilíbrio na separação dos Três Poderes da democracia, cunhada por Montesquieu, de tal forma que cria uma nova ordem de "juristocracia". Esta ordem é problemática porque implica um potencial de subverter a estrutura democrática pela delegação, aparentemente deliberada, de poder político ao único poder que não é legitimado democraticamente pelo sufrágio. Segundo Hirschl (2004, p. 65-67), a aceitação desta subversão se explica por três fatores: primeiro, a certeza que o judiciário vai produzir decisões que vão servir aos interesses majoritários da política; segundo, o controle político sobre a composição dos Supremos Tribunais; terceiro, o aproveitamento da confiança, herdada de longa data, na imparcialidade da justiça. Por meio de um amplo estudo de casos, o autor chega à conclusão que o processo de judicialização da política não é necessariamente um indício de uma mudança progressiva em defesa da democracia e da sociedade civil contra a máquina do Estado, como foi assumido pelo mainstream das Ciências Políticas (HIRSCHL, 2004, p. 212). Muito pelo contrário, permite a vertentes políticas a cômoda 
transferência de decisões pouco populares a um poder independente da vontade do eleitorado e que goza (ainda) de credibilidade, sendo que a elite judiciária, na verdade, representa as elites hegemônicas e, nas suas decisões, defende o estatus quo social (HIRSCHL, 2004, p. 165-166).

Mesmo que este argumento tenha sido elaborado com base em estudos realizados em outros países, as mesmas observações também são aplicáveis ao caso do Brasil (cf., p.ex., GALLO, 2009, p. 5; KOZICKI \& BARBOZA, 2016, p. 417). A própria base teórica da "judicialização da política" se mostra de hábil aplicabilidade ao caso brasileiro, por exemplo, pela afirmação de que um ambiente de paralisação política e de desencanto com a política seria a condição perfeita para a interferência judicial (TATE, 1995, p. 30-31). Também as três motivações para elevar a disposição política de usufruir da interferência do judiciário, que resultam da análise feita por HIRSCHL (2004, p. 214), combinam com a situação do Brasil atual: a ameaça da hegemonia política por novas preferências do eleitorado, a perda de confiança na classe política e a certeza de que as Cortes vão decidir de acordo com os interesses hegemônicos. Assim, o judiciário facilmente passa a ser visto como a última instância das expectativas de uma coletividade decepcionada, um "salvador da pátria":

[...] personalidades presumidamente desinteressadas, acima dos conflitos sociais, que, com pulso firme - às vezes despótico mesmo -, passem por cima de tudo e e de todos para 'por ordem na bagunça'. Essa ideologia tacanha, pré-moderna e particularista nutre-se de uma cultura política privatista, antirrepublicana, em que mesclam-se, em aparente paradoxo, a incapacidade de ação coletiva e o individualismo extremo, de um lado, e a aceitação resignada de desmandos e autoritarismos, de outro. (CAMPANTE, 2016, p. 125)

Há evidência de que esse novo papel não seja apenas projetado, mas produzido dentro das próprias novas doutrinas jurídicas que idealizam um Estado no qual se faz necessário que uma autoridade central, tida como eficaz e coerente, combine "a produção de regras, actividade de julgamento e o acompanhamento da aplicação das políticas" (COMMAILLE, 2009, p. 104).

Por outro lado, há de se levar em conta que o poder judiciário, de forma talvez ingênua, fora munido de poder para exercer melhor e potencialmente ampliar a sua função na sociedade. Já a Constituição “cidadã” de 1988 deu ampla autonomia ao judiciário (AVRITZER, 2016, p. 71). Por meio do fortalecimento das instituições de controle já existentes e da criação de novas instituições (cf. ARANTES 2011, 
FILGUEIRAS 2011, CORRÊA 2011), criou-se um “constitucionalismo emancipatório", pelo qual cidadãos comuns deveriam ganhar acesso aos benefícios da justiça. Houve, praticamente, um consenso de que o judiciário deve atuar para valer direitos fundamentais e que uma nova "cultura de direitos" deveria proteger a democracia, no sentido de defender reivindicações minoritárias contra a vontade majoritária (KOZICKI \& BARBOZA, 2016, p. 436). O judiciário pasou a ser visto como o aliado mais poderoso dos movimentos sociais (DOMINGO, 2010).

Entretanto, algo parece ter saído do controle, se compararmos este espírito de origem com a colocação, feita por um ministro do STF, de que

[...] o tribunal rompe um pouco com a postura que tradicionalmente chamávamos de legislador negativo e passa a ser também, ainda que provisoriamente, um legislador positivo, permitindo uma regulação provisória de uma dada situação que reclama disciplina normativa ou regulação. [...] Em geral estas atuações se dão em contextos de eventual faltas, lacunas ou omissões do próprio legislador. Ou às vezes em um certo estado de necessidade (MENDES, 2007).

O papel pró-ativo do judiciário, a partir de uma "lacuna" ou "necessidade" detectada na política, vai muito além do mandato da defesa de uma jovem democracia. Podem ser apelados para defender determinados interesses legítimos da volonté de tous, embora não atendidos politicamente, mas os juízes não foram eleitos para representar e executar a volonté générale, ou seja, simplesmente "não podem governar" (NATANSON, 2016). Não o podem, porque não há eleição para tirá-los do poder, nem estão à disposição os mais básicos mecanismos de accountability, pelos quais seria possível controlar os controladores (ARAGÃO, 2016). Controle, entretanto, é necessário, pois o próprio sistema jurídico sofre, da mesma forma que o político, dos males da morosidade, corrupção, ineficiência e do nepotismo. Os ministros do STF, como também qualquer ator político, são sujeitos a uma dimensão subjetiva e, como alertam Albuquerque e Holanda (2016, p. 456), "não exercem uma atividade absolutamente mecânica". O resultado é um intervencionismo jurídico que faz com que muitos juízes, "deslumbrados diante dos princípios e da possibilidade de através deles buscarem a justiça - ou o que entendem por justiça - passaram a negligenciar no seu dever de fundamentar racionalmente os seus julgamentos" (SARMENTO, 2007, p. 144). 
O caráter deliberado e pró-ativo do judiciário ficou óbvio durante a Ação Penal 470 (vulgo "mensalão") e, novamente, nas várias fases da operação Lava Jato. Ademais, o STF valeu-se, no julgamento do "mensalão", e continua o fazendo em outros processos, de outro mecanismo pertencente à judicialização da política no nível universal, que é a suposta aplicação de normas internacionais ou de outros sistemas jurídicos de prestígio primeiro-mundista a casos domésticos (LUTZ \& SIKKINK, 2001). A Corte justificou as sentenças, prominentemente, pela teoria alemã da Tat- und Organisationsherrschaft, adaptada e fusionada como "teoria do domínio do fato". Greco e Leite (2014), juristas brasileiros formados na Universidade de Munique e integrantes de um núcleo de pesquisa do próprio autor da teoria, Claus Roxin, chegam à conclusão, por meio de um estudo minucioso das 8000 páginas dos onze votos, que o STF não incorporou a teoria alemã, mas inventou uma teoria nova que unicamente justifica a culpabilidade pela posição de liderança, numa organização dentro da qual se cometem crimes, sem dolo, sem alguma ação concreta, apenas pela presunção de que o réu "deveria ter sabido". A pseudo-recepção da teoria alemã confere à decisão uma autoridade científica para imunizá-la contra quaisquer críticas.

\section{A politização da justiça}

A este ponto da argumentação torna-se evidente que a judicialização da política não pode ser analisada como um vetor unidirecional, mas sim como um campo de tensão que é caraterizado pela mutualidade de efeitos: a incorporação de processos jurídicos ao domínio do político e, ao mesmo tempo, a dominação de decisões políticas pelo jurídico, outrora competência apenas do executivo e legislativo (TATE, 1995, p. 28). Obviamente, qualquer interferência do judiciário em processos políticos, nos moldes acima expostos, concede automaticamente uma qualidade política à ação. Vale lembrar que, uma vez que a judicialização é estabelecida como praxe, também a repentina suspensão isolada de uma ação, outramente regular, constitui uma interferência pela própria omissão, que concede um tácito deferimento à respectiva decisão política. Portanto, o direito há de ser considerado per se uma ferramenta política (cf. DOUZINAS, 2009). Consequentemente, no presente trabalho, este argumento é considerado uma premissa e não uma hipótese. Tampouco se trata da politização no sentido de ausência de plena neutralidade ou presença de subjetividades em decisões. A 
teoria jurídica atual considera que o Direito é realizado por meio de uma "interpretação jurídica criativa-normativa" (AMARAL, 2005, p. 41), e não mais pela simples aplicação da norma a "fatos". As circunstâncias e condições destas interpretações despertaram a atenção das Ciências Sociais, nomeadamente na sua vertente da Teoria Crítica do Direito, com raízes na Teoria Crítica das Ciências Sociais da Escola de Frankfurt, que perpassa o limite entre Ciência Jurídica e Ciência Política. Esta ensinou que, além da legalidade dogmática tradicional do positivismo jurídico, existem determinantes sociopolíticas da atividade jurídica (WOLKMER, 2012, p. 42).

Por conseguinte, o sentido aqui empregado é de uma politização do jurídico stricto sensu, que se restringe ao uso de recursos e métodos próprios da esfera política pelos juristas. Este uso não constitui uma expansão, mas sim uma invasão do campo jurídico pelo político, cada um regido por regras distintas. No primeiro, as argumentações das partes devem ser públicas, os fatos verificados e julgados de acordo com uma norma geral e abstrata, as razões da decisão motivadas e o seu efeito restrito ao objeto tratado no processo. No segundo, a resolução das demandas legitima conchavos e compromissos que não se tornam públicos, os embates se resolvem pelo acolhimento da opinião da maioria e as decisões são tomadas, convenientemente e oportunamente, dentro do espectro de possíveis soluções políticas e numa circunstância social dada (DAMASCENO, 2005, p. 149-150). A clássica sistematização Luhmanniana já separou as duas áreas, embora mutuamente dependentes, segundo as funções que desenvolvem através de códigos distintos (cf., p. ex., LUHMANN, 1993, p. 124). O sistema jurídico que recorre a códigos externos, pelo uso de argumentos políticos, "opera em estado de corrupção"3 (LUHMANN, 1993, p. 81).

Entendo, portanto, a politização do jurídico como a assimilação de práticas e meios oriundos da esfera política. Esta se evidencia através de sintomas como, por exemplo, a tomada de posição política por meio de declarações públicas, às vezes com caráter paracomicial, sobre as quais Souza (2016, p. 118) alertou: “O juiz fala nos autos, e não na imprensa e nos jornais." Outro exemplo seria a especulação pública, por parte de integrantes do judiciário, sobre casos sob investigação, vazando informação sigilosa

\footnotetext{
3 “operiert im Zustand der Korruption” [tradução minha].
} 
(BONAN, 2015, p. 37-40). ${ }^{4}$ Dentro da constelação particular do mediascape brasileiro, estas pressunções se transformam em "verdades", mesmo que posteriormente desmentidas, e pautam a cena política por meio de uma "midiatização instrumental" (GUIMARÃES, 2016, p. 23 e 26).

\section{O “impeachment” como processo jurídico-político}

Estudar a politização da justiça pelo exemplo do "impeachment", movido contra Dilma Rousseff em 2016, exige algumas explicações prévias de caráter conceitual e metodológico. Em primeiro lugar, a própria denominação dada ao processo, reconhecida, sem muita divergência, no meio jurídico, indica a sua natureza mista, na liminar entre as esferas jurídica e política. Portanto, poderia tornar tautológica a comprovação das mútuas transgressões. Porém, como será mostrado, este processo jurídico-político não era um fenômeno híbrido, mas sim uma combinação de mecanismos jurídicos e políticos, o que não isenta a parte jurídica do rigor exigido no seu respetivo campo. De fato, este ponto foi alvo de amplas discussões na fase inicial do "impeachment", especialmente em relação à definição do rito. Houve quem argumentasse que o "impeachment", por ser julgado unicamente por um tribunal político, seria equivalente a qualquer processo decisório político. Objetou-se em contra que estas decisões políticas costumam apenas julgar o porvir, e não um ato pretérito com consequências punitivas a priori. Logo, o "impeachment", mesmo sendo conduzido no Congresso Nacional, seria um julgamento jurídico que deveria seguir todas as normas e princípios da prática do Direito. O STF, que foi consultado, entre outras ações, mediante a Arguição de Descumprimento de Preceito Fundamental (ADPF) n ${ }^{0}$. 378, sustentou, no acórdão do julgamento divulgado em 7 de março de 2016 (BRASIL 2016a, p. 59-62), que, embora a decisão caiba ao Senado, o processo intervem na esfera jurídica, especialmente no que diz respeito à garantia do devido processo e à caracterização do crime de responsabilidade nos termos da Constituição e da Lei 1.079/50 (cf. também BAHIA et al., 2016). Ou seja, se o processo de "impeachment" tem que seguir minimamente as regras básicas de um due process of law, e, se, para o processo ser legítimo, deve haver no mínimo provas de que foi cometido um dos crimes

\footnotetext{
${ }^{4}$ De forma profética, novamente SANTOS (2003) lembrou que "[n]ão deixa de ser paradoxal que, num momento político-judicial que se apresenta como de luta contra a tradicional impunidade dos poderosos, quem quer que tenha poder para violar o segredo de justiça o possa fazer impunemente."
} 
de responsabilidade previstos na legislação, então este possui necessariamente um sentido jurídico ao lado do político. Finalmente, a imprescindibilidade do elemento jurídico foi confirmada no próprio julgamento do "impeachment", oficializado na Resolução n ${ }^{o}$. 35/2016 do Senado Federal, assinada pelo presidente do STF "e do Processo de Impeachment", Ricardo Lewandowski, e pelos "Senadores que funcionaram como juízes" (BRASIL, 2016b, p. 2).

\section{Observações teóricas e metodológicas}

Partindo então da premissa de que o processo do "impeachment" há de se orientar pelo rito do processo legal, é preciso identificar, para realizar uma análise da "politização da justiça", elementos que respondem a esses requisitos. Nesta pesquisa, são os documentos legais produzidos durante o processo. Entre estes, destaca-se o libelo acusatório, por servir como base jurídica do julgamento como última fase do processo. Este foi redigido pelos mesmos autores da denúncia, os juristas Hélio Pereira Bicudo, Miguel Reale Júnior e Janaína Conceição Paschoal (BICUDO et al., 2016), e entregue ao Senado em 10 de agosto de 2016. O libelo acusatório, segundo a definição jurídica (cf., p. ex., MIRABETE, 1998), tem uma função ligada a julgamentos no Tribunal do Júri. Normalmente, é o requerimento produzido pelo Ministério Público cuja função é expor o fato criminoso e sua tipificação penal a fim de indicar o nome do réu, as circunstâncias agravantes previstas na lei e os fatos que devam influir na fixação da sanção, além de também apresentar um rol de testemunhas (REICHMANN, 2016, p. 75). Ou seja, o libelo é a principal peça da acusação a ser julgada pela tribuna e, portanto, considerado um documento importante que consolida, de fato, toda a acusação e as respectivas provas. No caso do "impeachment" contra a presidenta Dilma Rousseff, no qual o júri é composto pelos Senadores da República, o libelo cumpre uma função similar, com a diferença que a denúncia não parte do Ministério Público e sim dos solicitantes do pedido de "impeachment", idênticos aos autores do próprio libelo.

Para analisar o grau de politização presente neste documento jurídico, é necessário verificar antes as características regulares do gênero textual "libelo acusatório". O gênero é classificado como texto narrativo, descritivo e argumentativo, embora não dissertativo e injuntivo (PIMENTA, 2007, p. 130), ou seja, o texto narra acontecimentos como fatos e pretende convencer o interlocutor, entretanto sem explicar 
ou avaliar e livre de qualquer incitamento. Obviamente, a intenção persuasiva faz parte da natureza jurídica em qualquer documento, como alerta Ramos (2010, p. 14), o que torna impraticável um discurso absolutamente racional em Direito. O caráter retórico do discurso jurídico em si já fora reconhecido há tempo (SANTOS, 1988, p. 5). Mesmo assim, nota-se na redação de um libelo acusatório, diferente da denúncia e de outros textos jurídicos, "um esforço por demonstrar uma objetividade quase científica" (LIMA, 2006, p. 227), algo confirmado também pelo trabalho etnográfico em Tribunais do Júri realizado por Passos (2013). Certamente, textos jurídicos em geral são redigidos numa ritualizada linguagem de especialidade do âmbito do Direito. Contudo, o libelo, por se destinar a um Tribunal não especializado, mostra, via de regra, uma maior acessibilidade, algo que pode ser observado também no caso do libelo acusatório do “impeachment”. Entretanto, uma linguagem compreensível para os cidadãos comuns não implica, necessariamente, mais liberdade retórica.

É preciso, então, para corroborar a hipótese da politização do discurso jurídico no contexto do "impeachment", demonstrar que o texto, escolhido pela sua função central, se afasta significativamente da pretendida objetividade do gênero textual "libelo acusatório", por exemplo, pelo uso exacerbado de meios retóricos, e que, desta forma, exerce um maior poder persuasivo do que se fosse redigido conforme o padrão vigente. Vale lembrar que a veracidade dos fatos apresentados no libelo não estão sob análise neste trabalho, já que este empreendimento iria além do escopo da minha pesquisa. ${ }^{5} \mathrm{O}$ meu objetivo é unicamente analisar os mecanismos de argumentação do discurso e, para tal, me sirvo da metodologia da Análise Crítica do Discurso. Esta não oferece um conjunto único de métodos e sim uma grande variedade, devido ao seu caráter intrinsecamente interdisciplinar. Para atingir o meu objetivo, priorizo, entre os vários embasamentos teóricos e metodológicos disponíveis ${ }^{6}$, a abordagem desenvolvida, desde os anos 1980, pelo Instituto de Pesquisa Lingüística e Social de Duisburg (Duisburger

\footnotetext{
${ }^{5}$ Não obstante, para obter uma visão balanceada e integrada sobre o procedimento ou não dos "fatos" apresentados no libelo acusatório, vale verificar, além do Libelo Acusatório de nove páginas (BICUDO et al., 2016), a peça final da defesa ("Contrariedade ao Libelo"), de 673 páginas, entregue pelo advogado José Eduardo Cardozo ao Senado Federal no dia 12 de agosto de 2016 (CARDOZO, 2016a), e o último recurso ("Mandato de Segurança"), de 493 páginas, feito ao STF no dia 29 de setembro de 2016 (CARDOZO, 2016b), bem como os respectivos relatórios técnicos referidos nestes dois textos da defesa.

${ }^{6}$ A minha investigação não requer a inclusão de aspectos sociocognitivos e de recepção, como propostos na abordagem de van Dijk, nem o funcionamento sistêmico da linguagem, tal como abordado por Fairclough, para mencionar apenas dois representantes eminentes da Análise Crítica do Discurso, que por sua vez é uma especialização da grande área de Análise do Discurso.
} 
Institut für Sprach- und Sozialforschung, DISS) na Alemanha, até 2002 sob a direção de Siegfried Jäger. Desde então, o instituto tem produzido uma série considerável de estudos que analisam discursos políticos e midiáticos, com especial atenção àqueles motivados pelo extremismo de direita, xenofobia, racismo, antissemitismo e marginalização social, mesmo que sob o manto do aparentemente democrático (cf. JÄGER, 2009). A sua base teórica incorpora premissas foucaultianas como, por exemplo, a produção e sustentação, pelo poder e por meio do discurso, de uma verdade ("régime de la verité", cf. FOUCAULT, 1975 e 2001), a formação sistemática do próprio objeto do discurso pela prática discursiva, e a criação de coerência pelo uso de persuasivos símbolos coletivos (cf. FOUCAULT, 1969).

A análise de uma formação discursiva, segundo Jäger e Maier (2009), é conduzida em cinco níveis: 1) as linhagens temáticas na sua dimensão diacrônica e sincrônica; 2) os fragmentos discursivos que constituem uma linhagem; 3) os entrelaçamentos de linhagens em nódulos discursivos; 4) o contexto que produz eventos discursivos que as desencadeiam ou suportam; 5) sua expressão em vários âmbitos, por exemplo, político, midiático, acadêmico; 6) os posicionamentos que disto derivam em relação a um mesmo tema. Metodologicamente, uma análise básica (para os detalhes de uma análise completa, veja JÄGER, 2009) consiste de cinco passos: 1) a localização da linhagem temática (aqui discursos em favor do "impeachment”) e seus entrelaçamentos; 2) a sistematização dos fragmentos discursivos (textos) e, se possível, a seleção de um âmbito (aqui o político-jurídico); 3) a sistematização em relação a conteúdo e estrutura; 4) a análise de alguns fragmentos discursivos representativos, visando às estratégias e aos meios retóricos (por exemplo, estratégias de argumentação, lógica e composição, implicações e insinuações, simbolismo coletivo, estereótipos e metáforas, vocabulário e estilo, referências, etc.). Devido ao escopo do presente trabalho, limitarei as seguintes reflexões ao quarto procedimento, ou seja, a análise de um texto (o libelo acusatório) que, segundo a hipótese, exemplifica, de forma paradigmática, a função da formação discursiva em questão (a politização da justiça).

Para executar esta análise, recorro ao conjunto de ferramentas desenvolvidas pelo grupo de pesquisa de Análise Crítica do Discurso nas Universidades de Viena e Lancaster (cf. WODAK et al., 1999 e 2001, WODAK, 2013). A metodologia distingue 
entre estratégias discursivas ${ }^{7}$ principais e suas respectivas finalidades, como, por exemplo, de construção (unificar, identificar, delimitar), conservação (proteger, reafirmar, reproduzir) ou justificação (relativizar, restaurar), transformação (evolucionar, converter) e desmontagem (desqualificar, destruir). As estratégias se expressam por meio da retórica, especialmente pelo uso de lugares comuns ou topoi, que são realizados por meio da linguagem nos níveis pragmático, sintático e semântico. Os autores estabeleceram um catálogo que permite sistematizar o leque amplo de recursos da linguagem (WODAK et al., 1999, p. 79-93), mas como este aparato é imenso, os recursos serão explicados apenas no corpo da análise do libelo a seguir.

\section{Estudo de caso: o libelo acusatório do "impeachment"}

A estrutura do libelo acusatório segue, formalmente, a ordem prevista: saudação do destinatário; apresentação dos denunciantes; descrição do crime; atribuição de crimes de responsabilidade com sua respectiva classificação jurídica; indicação da pena prevista; nominação de testemunhas; subscrição dos denunciantes. Inclui, porém, nas páginas 2 a 6, e, novamente, na página 8 (ou seja, ocupando metade das 9 páginas), uma objeção longa à limitação do âmbito de análise da imputação contra a acusada, questionando a exclusão de supostos crimes praticados antes do mandato corrente e daquilo que comumente passou a ser chamado de "conjunto da obra", com base em discordantes interpretações de caráter jurídico. Este elemento, formalmente, não está previsto no gênero textual que deveria seguir à risca a denúncia tal como foi aceita pelo tribunal (ou seja, no caso do "impeachment", o relatório aprovado pelo Senado Federal). Portanto, merece atenção, já que poderia ser neste trecho, embora impertinente, que o libelo desenvolva a sua força persuasiva. Retirando os trechos meramente protocolares e técnicos (fórmulas de saudação, citações da Constituição e da Lei 1.079/50), que praticamente não permitiam aos autores uma redação personalizada, restam 6,5 páginas para a análise.

\footnotetext{
${ }^{7}$ Estratégias no sentido de Bourdieu, ou seja, direcionadas, mas não rigidamente calculadas e instrumentalistas; como expressão, às vezes quase automatizada, da relação entre habitus e campo. Portanto, o uso destas estratégias por parte dos autores do libelo não é necessariamente motivado pelo objetivo de manipular, mas sim, provavelmente, pela crença que estas veiculem "a verdade".
} 
Já na primeira página chama a atenção uma clássica estratégia de desmontagem, quando insinua que a acusada seria responsável pela "omissão diante do maior escândalo de corrupção do mundo" (BICUDO et al., 2016, p. 1, todas as ênfases, também a seguir, são minhas). O superlativo hiperbólico constrói, sem ser suportado por evidência alguma, um locus terribilis que funciona, pelo teor normativo-deôntico da enunciação, como argumentum ad baculum e, ao mesmo tempo, como locus a tempore. Ou seja, a existência do maior caso de corrupção a nível mundial constitui uma ameaça, e um Governo que o omite há de ser deposto quanto antes possível ${ }^{8}$. A estratégia é afirmada por outra colocação que aponta para "fraudes [...], perpetradas aos bilhões" (BICUDO et al., 2016, p. 2). Esta, além de fazer novamente uso da hipérbole e de um topos de vagueza referente aos números, com função de ênfase, as imputa indiretamente à presidenta pela omissão do agente na construção participial. $\mathrm{O}$ uso estratégico da omissão, desta vez em termos de finalidade, está presente em outro exemplo que denuncia a "tomada de empréstimos" (BICUDO et al., 2016, p. 1) e que o Governo “utilizou recursos dos bancos públicos" (BICUDO et al., 2016, p. 2). O evitamento desta informação e a simplificação cria uma analogia com o saber cotidiano sobre movimentações financeiras e as associa às corriqueiras narrativas de corrupção que servem como antimiranda. Em consequência, insinua, sem dizê-lo abertamente (e sem poder prová-lo), não apenas o uso ilegal desta verba, mas o seu uso (leia-se: roubo) para fins próprios do Governo, do partido ou até particulares da própria acusada.

Além da desmontagem, algo previsível pela atitude dos denunciantes, chamam a atenção as estratégias de construção, mais precisamente a desassimilação do Brasil em dois polos antagônicos. Por um lado, os brasileiros, e por outro um grupo conspirativo, ligado à acusada, que se caracteriza pela delinqüência: "muitos dos agentes presos e até condenados [...] são intimamente ligados ao Partido dos Trabalhadores, sigla da Presidente da República” (BICUDO et al., 2016, p. 8). Embora o direito brasileiro não preveja a sippenhaftung nazista que estendia a responsabilidade penal a familiares, amigos e associados, o locus a maiore inculca uma inclusão funda - afinal, quem é íntimo, compartilha todos os segredos - que funciona como uma difamação da acusada

\footnotetext{
${ }^{8}$ Embora não seja objeto da minha análise, não posso deixar de registrar a surpreendente ignorância de casos de corrupção precedentes que, sendo bem documentados, uma breve revisão bibliográfica teria levado à tona, além de observar o profundo provincialismo que tal declaração dogmática revela na sua referência ao contexto internacional.
} 
ad hominem. A mesma função cumpre a menção do "Petrolão, em cujo âmbito foram investigadas, processadas e até condenadas pessoas muito próximas à Senhora Presidente" (BICUDO et al., 2016, p. 1), só que por um topos de assimilação. Chamam a atenção, em ambas as citações, a vagueza referencial à quantidade e qualidade (“muitos dos agentes", "muito próximas"). Com mais precisão, o ex-presidente da Câmara, Eduardo Cunha, é incluído entre os membros da quadrilha da acusada, já que "inegavelmente, auxilou-a ao despachar reduzindo a denúncia, conferindo à defesa argumento para furtar-se a enfrentar relevantes imputações" (BICUDO et al., 2016, p. 2). Já afastado da presidência da Câmara no momento da redação do libelo e cunhado, pela mídia, como corrupto-mor, passa a cumprir a função de assimilar a presidenta à sua figura e, inclusive, a insinuar uma aliança entre os dois que permita que as acusações contra Dilma Rousseff sejam “extirpadas” (BICUDO et al., 2016, p. 2).

A construção de dois grupos opostos atinge o seu auge quando o libelo, na página 8 , retoma a digressão impertinente e anuncia que "não tivesse a acusação referente ao Petrolão sido alijada do processo, poder-se-ia mostrar que [...]" (BICUDO et al., 2016, p. 8). A metáfora náutica do alijamento, geralmente uma medida para escapar de um perseguidor, é retomada em seguida e atribui à presidenta "o saque à Petrobras" (BICUDO et al., 2016, p. 8), "antigo orgulho nacional" (BICUDO et al., 2016, p. 8). Pela sinédoque, a Petrobras passa a simbolizar, pars pro toto, a nação brasileira sob ataque e até "sangrada" (BICUDO et al., 2016, p. 8) por saqueadores (piratas?) pintados como não-nacionais através da heteronomização metafórica ${ }^{9}$. A metáfora desliza para a catacrese quando, em seguida, transforma os piratas nos seus mais temidos antagonistas, "algozes do povo brasileiro" (BICUDO et al., 2016, p. 8). Este locus a nominis interpretatione draconiano alerta, numa clássica estratégia Cassandra, para o desastre num futuro próximo.

A situação não deixa de ser menos periclitante se lembrarmos que, na visão dos autores do libelo acusatório, antes da planejada execução dos brasileiros, veio a sua traição. Fazendo uso de estratégias de transformação, instilam que o Brasil estaria à

\footnotetext{
${ }^{9}$ Outra vez, não posso deixar de registrar a curiosidade desta declaração, em especial em face às retalhações e privatizações que o tal "antigo orgulho nacional" vem sofrendo desde que foi resgatado das mãos dos "saqueadores". O uso do verbo "sangrar" também é curioso, pois cria uma imediata associação com as conversas, entre o então Ministro de Planejamento, Romero Jucá, e o ex-presidente da Transpetro, Sérgio Machado (ocorridas em março de 2016, gravadas ocultamente e tornadas públicas em 23 de maio de 2016), nas quais concordam que uma "mudança" no Governo Federal possibilitaria "estancar a sangria" representada pela Operação Lava Jato.
} 
beira de um abismo e, portanto, precisando de uma mudança de rumo, mesmo que esta seja penosa. A acusada, por supostamente ter manipulado a contabilização das finanças públicas, "impossibilitou que a população tivesse exata dimensão da real situação econômica e financeira do país" (BICUDO et al., 2016, p. 1). A suposição da existência de uma "real" situação econômica, escondida do povo brasileiro (e, aparentemente, de todos os economistas do país), sugere uma coerção fatual (e, novamente, um locus a tempore) que não deixa alternativa a políticas de austeridade. A mensagem é agravada pelo argumentum ad baculum que o Governo criou "nos eleitores a falsa sensação de que o país dispunha de dinheiro para dar continuidade aos Programas alardeados nos palanques" (BICUDO et al., 2016, p. 2). Deixando novamente de lado a pergunta, fora do escopo da análise, sobre quanto dinheiro o Brasil dispõe (ou poderia dispor por meio de uma arrecadação efetiva) e para quais finalidades este dinheiro poderia ser gasto, vemos que, nestes trechos, a palavra "Governo" é usada sistematicamente como metonímia para a presidenta acusada. Além de gabadora, ela é caraterizada como pessoa que age de má-fé e quase com prazer mefistófilo, "com o fim de iludir a população" (BICUDO et al., 2016, p. 2), em suplementação da estratégia de transformação com novas desmontagens: "é certo que a Presidente/Candidata já sabia que o cumprimento de tal compromisso seria impossível" (BICUDO et al., 2016, p. 2). Paralelamente à sua associação a um grupo delinquente, como foi mostrado acima, a delinquência é personificada nela, como também na "edição de decretos" (BICUDO et al., 2016, p. 1), palavra cuidadosamente escolhida em lugar de sinônimos como "autorização" ou "assinatura", que implicariam sutilmente um grau menor de autoria única.

A estratégia de transformação, em forma de descontinuação, atinge seu auge na formulação, no tempo presente e encerrada com ponto de exclamação, "cumpre aos Senadores buscar a verdade real (e não apenas a formal), pelo bem do país!” (BICUDO et al., 2016, p. 3). O locus a tempore sugere que tenha chegado o momento certo para uma mudança, se não o país correria até o risco de ter a sua estrutura democrática desmantelada, como alegou já antes, pela "afronta à separação de poderes" (BICUDO et al., 2016, p. 1). Esta “afronta", expressão hiperbólica, sinônima à ofensa e injúria, seria evidenciada apenas pela assinatura de decretos sem a "devida autorização do Congresso Nacional" (BICUDO et al., 2016, p. 1), sem levar em consideração que os créditos foram aprovados, como tem sido de praxe, ex posteriori, o que faz do adjetivo "devido" 
um disfemismo para "prévio". Apesar de insistir aqui justamente nas formalidades protocolares, mais ou menos flexíveis, do processo legislativo, o libelo visa um valor maior, se bem que ainda mais vago na sua apuração, que é o "princípio da MORALIDADE” (BICUDO et al., 2016, p. 5), única palavra grifada em caixa alta, no texto inteiro, com efeito forte de ênfase. A acusação da presidenta de um comportamento amoral (ou até imoral) é, mais uma vez, uma difamação ad hominem e lembra uma estratégia de opressão, amplamente usada durante a ditadura militar no Brasil, na qual foram censurados, perseguidos e punidos, com base no Decreto-Lei 1077/70, vozes dissonantes: não pelo seu teor político, mas por terem cometidos atos contrários à moral e aos bons costumes.

O libelo acusatório inclui uma série de expressões que dão ênfase e intensidade aos próprios argumentos. Quando abona que o roubo aos bancos públicos "restou limpidamente evidenciado" (BICUDO et al., 2016, p. 2), usa um advérbio que sugere certeza onde há, mesmo entre especialistas da área, dúvidas pesadas. Já um outro exemplo, que assevera que "o pagamento das pedaladas foi operacionalizado de maneira completamente irregular" (BICUDO et al., 2016, p. 7), faz surgir a dúvida se, então, existem, ao lado das operações completamente irregulares, outras maneiras apenas irregulares. Aqui a ênfase melindrosa tem caráter de ato falho, já que todas as acusações tomam como régua apenas a norma legal, fingindo que não haja uma discrepância em relação à aplicação prática dentro de estruturas políticas persistentes, o que, consequentemente, deveria se refletir na sua avaliação legal. Mesmo assim, pela ênfase feita de maneira inconsciente, os autores do libelo aparentam estar ainda cientes desta realidade. Outras estratégias de justificação incluem a legitimação das próprias opiniões pelo argumentum ad verecundiam. Encontramos, entre várias autoridades citadas, o "saudoso Ministro Paulo Brossard", novamente homenageado como o "sempre Professor Brossard", além de "outros consagrados juristas pátrios" (BICUDO et al., 2016, p. 2-3 ${ }^{10}$. Se há juristas patriotas, deve haver, na lógica do libelo, outros apatriotas, supostamente a serviço dos já mencionados usurpadores do Brasil. O teor

\footnotetext{
${ }^{10}$ A maioria das autoridades jurídicas é citada no libelo (BICUDO et al., 2016, p. 4 e 5) de uma única fonte: "Impeachment: um instrumento da democracia", publicado, pontualmente em abril de 2016, pelo Instituto dos Advogados de São Paulo (IASP), e organizado por Ives Gandra da Silva Martins, Dircêo Torrecillas Ramos, José Horácio Halfeld Rezende Ribeiro, Mayr Godoy e Sergio Ferraz. Constam entre os 19 colaboradores do volume os três autores do libelo acusatório, além do "engavetador-geral" da República, Geraldo Brindeiro (MARTINS et al., 2016).
} 
populista desta declaração é reforçado pela última justificativa, antes de pedir a devida punição de Dilma Rousseff: “O conjunto probatório [...] é contundente. Não fosse, três gerações, representadas pelos denunciantes, não teriam se se unido para defender a ordem jurídica do país” (BICUDO et al., 2016, p. 8). Bastaria voltar um pouco na história para lembrar momentos nos quais três gerações se uniram para alcançar um objetivo (e nem precisamos logo pensar no holocausto), mesmo que sem prova contundente alguma. Já que a garantia em termos de legitimidade é nula, tal qual o argumento que sustenta a justificativa, apenas sugere uma lógica pelo uso de um topos de continuação.

\section{Considerações finais}

A síntese dos resultados da análise permite corroborar a hipótese que o poder persuasivo do libelo acusatório emana, principalmente, da habilidade retórica de encenar uma argumentação, sem que haja a necessidade de esclarecer os argumentos e apresentar evidência. Como foi explicado anteriormente, não existe argumentação sem retórica. Portanto, é a presença desmesurada da retórica que sugere, segundo a base teórica, a existência de uma incoerência no nível argumentativo (e a sua base factual) a ser resguardada. Como tal, este resultado permite tirar conclusões sobre a politização deste documento jurídico, considerando as premissas adotadas em relação às funções do campo jurídico e político e as caraterísticas do gênero textual: trata-se, na verdade, de um pseudo-libelo acusatório (que tem que ser colocado entre aspas daqui em diante). Sendo assim, desqualifica a dimensão jurídica do "impeachment", pelo menos no tocante a este documento que, como foi mostrado, ocupa uma posição chave em todo o processo.

Em relação à judicialização da política e da politização da justiça, podemos, a partir do caso analisado, constatar uma dinâmica preocupante nas mútuas interferências dos dois campos. Por um lado, o caráter "político-jurídico" do processo, que, segundo a teoria e a cobertura midiática, garantiria o controle pela objetividade das normas jurídicas, se revelou apenas uma dissimulação, dando uma figura jurídica a um procedimento que segue, no "libelo acusatório", as regras do campo político. É preocupante que, num contexto no qual a interferência do judiciário na política é praxe aceita e quase esperada, o STF, apesar de ter desenvolvido acionismo jurídico em outras 
ocasiões, tenha apoiado tacitamente, pela omissão, o pseudo-processo político-jurídico, sabendo da seriedade das implicações políticas que provocaria.

Em resumo, se o processo do "impeachment" tivesse sido um ato meramente político, teria sido inconstitucional e, como tal, provavelmente não teria sido viável, por não ter alcançado uma ampla aceitação por parte da sociedade brasileira. Se tivesse sido de fato um processo jurídico-político, poderia ou não ter possibilitado a condenação da presidenta Dilma Rousseff por crime de responsabilidade, ao depender da apuração jurídica dos fatos apresentados, que não foram contemplados neste trabalho. Pela análise feita, o afastamento da presidenta do cargo, tal como foi realizado pelo processo que culminou na Resolução $n^{\circ}$. 35/2016, apenas foi possível pela politização stricto sensu do componente jurídico. Em relação ao "libelo acusatório", esta implicou a extinção, salvo o rito, das regras essenciais do campo jurídico e, consequentemente, uma autodesqualificação do due process of law. O caso brasileiro do "impeachment" mostra que a nova relação íntima entre um judiciário empoderado e interesses políticos, ao contrário de promover um constitucionalismo emancipatório, pode resultar, nas oscilações observadas e ao depender das orientações políticas adotadas pelo jurídico, na legitimação de uma ação inerentemente política, ou seja, usando novamente as já citadas palavras de Luhmann, operando em estado de corrupção. Assim sendo, o fenômeno da politização da justiça não constitui apenas um "tropeço da democracia", como reconheceu, em prudente retrospectiva, o Ministro do STF e presidente do processo do “impeachment”, Ricardo Lewandowski (CAROS AMIGOS, 2016), mas uma severa e constante ameaça ao Estado de Direito e ao funcionamento da democracia com consequências já manifestas, embora ainda ignotas na sua plena dimensão.

\section{REFERÊNCIAS}

ALBUQUERQUE, N. de Menezes; HOLANDA, F. Rodrigues. O Ativismo Judicial como fenômeno legítimo da democracia. In: GUIMARÃES, J.; OLIVEIRA, M. Andrade Cattoni de; LIMA, M. Mont'Alverne Barreto; ALBUQUERQUE, N. de Menezes (orgs.). Risco e Futuro da Democracia Brasileira: Direito e Política no Brasil Contemporâneo. São Paulo: Fundação Perseu Abramo, 2016. p. 443-463.

AMARAL, F. A interpretação jurídica segundo o Código Civil. Revista Brasileira de Direito Comparado, Rio de Janeiro, nº. 29, p. 19-41, 2005.

ARAGÃO, E. É importante lembrar que, numa república, ninguém pode se eximir de controles. Consultor Jurídico, São Paulo, 2 dez. 2016. Disponível em: 
<http://www.conjur.com.br/2016-dez-02/eugenio-aragao-numa-republica-ninguemeximir-controles>. Acesso em: 10 fev. 2017.

ARANTES, R. Bastos. Polícia Federal e construção institutcional. In: AVRITZER, L.; FILGUEIRAS, F. (orgs.). Corrupção e Sistema Político no Brasil. Rio de Janeiro: Civilização Brasileira, 2011. p. 99-132.

AVRITZER, L. Autonomia do Judiciário versus Pretorianismo Jurídico-Midiático. In: GUIMARÃES, J.; OLIVEIRA, M. Andrade Cattoni de; LIMA, M. Mont'Alverne Barreto; ALBUQUERQUE, N. de Menezes (orgs.). Risco e Futuro da Democracia Brasileira: Direito e Política no Brasil Contemporâneo. São Paulo: Fundação Perseu Abramo, 2016. p. 71-82.

BAHIA, A. G. Melo Franco; SILVA, D. Bacha e; OLIVEIRA, M. Andrade Cattoni de. Impeachment: Apontamentos à decisão do STF na ADPF n. 378. In: GUIMARÃES, J.; OLIVEIRA, M. Andrade Cattoni de; LIMA, M. Mont'Alverne Barreto; ALBUQUERQUE, N. de Menezes (orgs.). Risco e Futuro da Democracia Brasileira: Direito e Política no Brasil Contemporâneo. São Paulo: Fundação Perseu Abramo, 2016. p. 159-175.

BICUDO, H. Pereira; REALE JR., M.; PASCHOAL, J. Conceição. Libelo Acusatório. Brasília, Senado Federal, 10 ago. 2016. Disponível em: http://www.senado.leg.br/atividade/rotinas/materia/getPDF.asp?t=198410\&tp=1.

Acesso em: 10 fev. 2017.

BONAN, A. C. Faro. Antinomia na hidráulica da democracia: a hermenêutica dos vazamentos. Insight Inteligência, Rio de Janeiro \& São Paulo, vol. 18, nº 70, p. 16-41, 2015.

BRASIL. Supremo Tribunal Federal. Medida Cautelar na Arguição de Descumprimento de Preceito Fundamental (ADPF) no 378/DF - Distrito Federal. Relator: Ministro Edson Fachin. Diário da Justiça Eletrônico, no 43, Plénário, Acórdãos, 7 mar. 2016a, p. 59-62. Disponível em: <http://www.stf.jus.br/portal/geral/verPdfPaginado. asp?id=10447206\&tipo=DJ\&descricao=DJE\%20N\%C2\%BA\%2043\%20\%2007/03/2016>. Acesso em: 10 fev. 2017.

BRASIL. Senado Federal. Resolução n ${ }^{\circ}$. 35, de 2016. Dispõe sobre sanções no Processo de Impeachment contra a Presidente da República, Dilma Vana Rousseff, e dá outras providências. Diário Oficial, Brasília, DF, edição extra, seção 1, 31 ago. 2016b, p. 1-2.

CAMPANTE, R. Goyatá. Justiça, corrupção e democracia: Reflexões em torno da operação Lava Jato. In: GUIMARÃES, J.; OLIVEIRA, M. Andrade Cattoni de; LIMA, M. Mont'Alverne Barreto; ALBUQUERQUE, N. de Menezes (orgs.). Risco e Futuro da Democracia Brasileira: Direito e Política no Brasil Contemporâneo. São Paulo: Fundação Perseu Abramo, 2016. p. 83-142.

CARDOZO, J. E. Contrariedade ao Libelo. Brasília, Senado Federal, 12 ago. 2016a. Disponível em: http://www.senado.leg.br/atividade/ rotinas/materia/getPDF.asp?t=198541\&tp=1. Acesso em: 10 fev. 2017. 
CARDOZO, J. E. Mandato de Segurança. Brasília, Superior Tribunal Federal, 29 set. 2016b. Disponível em: <https://d2f17dr7ourrh3. cloudfront.net/wpcontent/uploads/2016/09/MS-JUSTA-CAUSA_29092016_22h05_final-2.pdf>. Acesso em: 10 fev. 2017.

CAROS AMIGOS. Em aula, Lewandowski classifica impeachment de "tropeço na democracia", Caros Amigos, São Paulo, 28 set. 2016. Disponível em: $<$ http://carosamigos.com.br/index.php/politica/7957-em-aula-lewandowski-classificaimpeachment-de-tropeco-na-democracia>. Acesso em: 10 fev. 2017.

COMMAILLE, J. O modelo de Janus da regulação jurídica. o carácter revelador das transformações do estatuto político da justiça. Revista Crítica de Ciências Sociais, Coimbra, $\mathrm{n}^{0} .87$, p. 95-119, 2009.

CORRÊA, I. Moreira. Sistema de integridade: avanços e agenda de ação para a administração pública federal. In: AVRITZER, L.; FILGUEIRAS, F. (orgs.). Corrupção e Sistema Político no Brasil. Rio de Janeiro: Civilização Brasileira, 2011. p. 163-190.

DAMASCENO, J. Batista. Justiça como poder: Judicialização da política, politização da justiça e pessoalização da jurisdição. Dissertação (Mestrado em Ciência Política) Instituto de Filosofia e Ciências Sociais, Universidade Federal do Rio de Janeiro, Rio de Janeiro, 2005.

DOMINGO, Pilar. Novel Appropriations of the Law in the Pursuit of Political and Social Change in Latin America. In: Couso, Javier A.; Huneeus, Alexandra; Sieder, Rachel (orgs.). Judicialization and Political Activism in Latin America. New York: Cambridge University Press, 2010. p. 254-278.

DOUZINAS, C. O Fim dos Direitos Humanos. São Leopoldo: Ed. Unisinos, 2009.

FILGUEIRAS, F. Transparência e Controle da Corrupção no Brasil. In: AVRITZER, L.; FILGUEIRAS, F. (orgs.). Corrupção e Sistema Político no Brasil. Rio de Janeiro: Civilização Brasileira, 2011. p. 133-162.

FOUCAULT, M. L'Archéologie du savoir. Paris: Gallimard, 1969.

FOUCAULT, M. Surveiller et punir. Naissance de la prison. Paris: Gallimard, 1975.

FOUCAULT, M. La fonction politique de l'intellectuel. In: Defert, D. \& Ewald, F. (orgs.). Dits et écrits II, 1976-1988. Paris: Gallimard. 2001. p. 109-114.

GALLO, C. A. Algumas considerações sobre a judicialização da política na América Latina. Revista Brasileira de História \& Ciências Sociais, São Leopoldo, vol. 1, nº 2 , p. 1-11, 2009.

GRECO, L.; LEITE, A. O que é e o que não é a teoria do domínio do fato. sobre a distinção entre autor e partícipe no direito penal. In: GRECO, L.; LEITE, A.;

TEIXEIRA, A.; ASSIS, A. (orgs.). Autoria como domínio do fato: estudos introdutórios sobre o concurso de pessoas no direito penal brasileiro. São Paulo: Marcial Pons, 2014, p. 19-46. 
GUIMARÃES, Juarez 2016. Midiatização Instrumental versus Publicidade Democrática na Operação Lava Jato. In: GUIMARÃES, J.; OLIVEIRA, M. Andrade Cattoni de; LIMA, M. Mont'Alverne Barreto; ALBUQUERQUE, N. de Menezes (orgs.). Risco e Futuro da Democracia Brasileira: Direito e Política no Brasil Contemporâneo. São Paulo: Fundação Perseu Abramo, 2016. p. 19-32.

HIRSCHL, R. Towards Juristocracy: The Origins and Consequences of the New Constituionalism. Cambridge, Massachusetts \& London, England: Harvard University Press, 2004.

JÄGER, S. Kritische Diskursanalyse: Eine Einführung. Münster: Edition DISS \& Unrast-Verlag, 2009 [1999].

JÄGER, S.; MAIER, F. Theoretical and methodological aspects of Foucaultian critical discourse analysis and dispositive analysis. In: WODAK, R.; MEYER, M. (orgs.). Methods of Critical Discourse Analysis. London: Sage, 2009. p. 34-61.

KOZICKI, K.; BARBOZA, E. M. de Queiroz. Democracia Constitutcional, Ativismo Judiciale Controle Judicial de Políticas Públicas. In: GUIMARÃES, J.; OLIVEIRA, M. Andrade Cattoni de; LIMA, M. Mont'Alverne Barreto; ALBUQUERQUE, N. de Menezes (orgs.). Risco e Futuro da Democracia Brasileira: Direito e Política no Brasil Contemporâneo. São Paulo: Fundação Perseu Abramo, 2016. p. 417-441.

LIMA, H. M. Rodrigues de. Na tessitura do Processo Penal: a argumentação no Tribunal do Júri. Tese (Doutorado em Lingüística) - Faculdade de Letras, Universidade Federal de Minas Gerais, Belo Horizonte, 2006.

LUHMANN, N. Das Recht der Gesellschaft. Frankfurt am Main: Suhrkamp, 1993.

LUTZ, E.; SIKKINK, K. The Justice Cascade: The Evolution and Impact of Foreign Human Rights Trials in Latin America. Chicago Journal of International Law, Chicago, vol. $2, n^{\circ} .1$, p. 1-33, 2001.

MARTINS, I. G. da Silva; RAMOS, D. Torrecillas; RIBEIRO, J. H. Halfeld Rezende; GODOY, M.; FERRAZ, S. Impeachment: um instrumento da democracia. São Paulo: Ed. IASP, 2016.

MENDES, G. F. Revolução silenciosa: Judiciário passa por processo de reengenharia, diz Gilmar Mendes [entrevista]. Revista Consultor Jurídico, São Paulo, 18 out. 2007. Disponível em: <http://www.conjur.com.br/2007-out-18/judiciario_passa_processo_ reengenharia? pagina $=2>$. Acesso em: 10 fev. 2017.

MIRABETE, J. F. Processo Penal. São Paulo: Atlas, 1998.

NATANSON, J. A judicialização da política e a politização da justiça. Observatório da Imprensa, $\quad \mathrm{n}^{\circ}$. 927, 10 maio 2016. Disponível em: <http://observatoriodaimprensa.com.br/jornal-de-debates/ judicializacao-da-politica-epolitizacao-da-justica/>. Acesso em: $10 \mathrm{fev} .2017$. 
PASSOS, T. E. de Lima. O espetáculo da Justiça: uma etnografia do Tribunal do Júri. Tese (Doutorado em Antropologia) - Instituto de Ciências Sociais, Universidade de Brasília, Brasília, 2013.

PIMENTA, V. Raposo. Textos forenses: um estudo de seus gêneros textuais e sua relevância para o gênero. Dissertação (Mestrado em lingüística) - Instituto de Letras e Lingüística, Universidade Federal de Uberlândia, Uberlândia, 2007.

RAMOS, E. da Costa. O Coelho da Cartola: análise argumentativa da linguagem jurídica. Dissertação (Mestre em Letras) - Faculdade de Letras, Pontifícia Universidade Católica do Rio Grande do Sul, Porto Alegre, 2010.

REICHMANN, T. Denúncia e Anklageschrift: um estudo contrastivo. Language and Law / Linguagem e Direito, Porto \& Florianópolis, vol. 3, nº 1, p. 71-88, 2016.

SANTOS, B. de Sousa. O discurso e o poder: ensaio sobre a sociologia da retórica. Porto Alegre: Sérgio Antonio Fabris Ed., 1988.

SANTOS, B. de Sousa. A judicialização da política. Público, Lisboa, 26 maio 2003. Disponível em: <https://www.ces.uc.pt/opiniao/bss/ 078.php>. Acesso em: $10 \mathrm{fev}$. 2017.

SARMENTO, D. Ubiqüidade Constitucional: Os Dois Lados da Moeda. In: SARMENTO, D.; SOUZA NETO, C. Pereira de (orgs.). A Constitucionalização do Direito: Fundamentos Teóricos e Aplicações Específicas. Rio de Janeiro: Lúmen Júris, 2007. p. 113-148.

SOUZA, J. A radiografia do golpe. Rio de Janeiro: LeYa, 2016.

TATE, C. Neal. Why the Expansion of Judicial Power? In: TATE, C. Neal; VALLINDER, Torbjörn (orgs.). The Global Expansion of Judicial Power. New York, London: New York University Press, 1995. p. 27-37.

VALLINDER, Torbjörn. When the Courts Go Marching In. In: TATE, C. Neal; VALLINDER, Torbjörn (orgs.). The Global Expansion of Judicial Power. New York, London: New York University Press, 1995. p. 13-26.

WODAK, R.; CILLIA, R. de; REISIGL, M.; LIEBHART, K. The Discursive Construction of National Identity. Edinburgh: University Press, 1999.

WODAK, R.; MEYER, M. Methods of Critical Discourse Analysis. London: Sage, 2001.

WODAK, R. (org.). Critical Discourse Analysis. 4 volumes. London: Sage, 2013.

WOLKMER, A. C. Introdução ao Pensamento Jurídico Crítico. São Paulo: Saraiva, 2012. 